Iranian Journal of Pathology | ISSN: 2345-3656

\title{
The Effect of Lavandula Stoechas on Toxigenesis and the Growth of Vibrio Parahaemolyticus
}

\author{
Omid Maghsoudi', Mohsen Zeraatkar ${ }^{1}$, Mojtaba Dolatabadi', Ahmad Johari', Mahdi Barati Karizno ${ }^{2}$, \\ Reza Ranjbar ${ }^{*}$ \\ 1. Doctor of Veterinary Medicine, Faculty of Veterinary Medicine, Islamic Azad University, Karaj Branch, Iran \\ 2. Dept. of Food Hygiene, Ferdowsi University of Mashhad, Mashhad, Iran \\ 3. Molecular Biology Research Center, Baqiyatallah University of Medical Sciences, Tehran, Iran
}

\begin{tabular}{c}
\hline KEYWORDS \\
\hline Lavender Essence; \\
Bacterium Growth; \\
Toxin Formation; \\
Vibrio Parahaemolyticus \\
\\
\hline
\end{tabular}

\section{Article Info}

Received 05 Feb 2017; Accepted 03 July 2018; Published Online 17 July 2018;

\section{ABSTRACT}

Background \& objective: Outbreak of food-borne diseases has become more and more important these days and using natural food preservers with high durability is under debate. Vegetative essence is a type of food preserver and many studies have been performed on their antimicrobial effects. The purpose of this study wasto investigate antibacterial effects of lavender essence on toxigenesis and the growth of Vibrio Parahaemolyticus.

Methods: lavender essence was prepared and its components were identified using GCMS. Determining minimum interceptorgrowth of Vibrio parahaemolyticus was assessed in test tubes containing BHI. Thermal resistant hemolysin was measured by Kap-RPLAkit. Growth diagram was prepared after determining toxin formation titration of the bacterium during $0,2,3,4,6,8$ and 24 hours.

Results: Cineol, Borneol, Camphor, LinaloolL and Alpha-pinen had the highest concentrations in the essence, respectively. Results of minimum intercepter concentration of lavender $(0,0.005,0.015,0.03$ and 0.045 percent) on Vibrio parahaemolyticus showed that $0.03 \%$ and higher concentrations had the ability to prevent growth and toxin formation of Vibrio parahaemolyticus. In addition, the effect of different concentrations of essence on toxin titration of bacterium showed no toxin at concentrations of 0.030 and 0.045 .

Conclusion: lavender essence was able to prevent the growth and toxin formation of Vibrio parahaemolyticus. 


\section{Introduction}

Modern economic and social changes along with international food trade at universal level have deployed the risk of many food borne diseases. However, producing a healthy food with high durability indicates the necessity of using food preservers. In the recent years, food manufacturers have paid great attention to natural preservers instead of chemical ones due to their unfavorable effects such as being carcinogen, teratogen, acute food poisoning and longterm degradation. Herbal essences have been considered by food health researchers in the recent years and many studies have been focused on their antimicrobial and preservative characteristics. Essences or their components have wide spectrum of antibacterial potency and have anti-parasite, insecticide, antiviral, anti-fungal and antioxidant characteristics $(1,2)$. Essences have the most antibacterial activity if prepared from flowering plants or closely after it. On the other hand, plants of the same species grown in different conditions can have distinctive chemical characteristics and combinations (3).

Approximately, 3000 types of essences have been identified, among which about 300 types are important from commercial aspects. FDA (Food and Drug Administration) has also confirmed essences as food preservative and additive (4). Currently, most common applications of essences in the European Union is related to food industries (as flavors), cosmetics and pharmacy industry (for different applications such as making disinfectants, dental filing material, nutritional supplements, etc.) (5).

Based on chemical structure, active compounds of essences can be classified into three main classes of Terpenes, Terpenoids and Phenyl Propens (6). Terpenoids include thymol, carvacrol, linalool, linalyl acetate, citronellal, piperitone, menthol and geraniol $(7,8)$. Antimicrobial performance of carvacrol, thymol, linalool and menthol against Listeria monocytogenes, Enterobacter aerogenes, Escherichia coli and Pseudomonas aeruginosa has been studied and the most active antimicrobial compounds were carvacrol and then thymol $(9,10,11)$.
Thymol effect on Salmonella typhi form and Staphylococcus aureus was studied showing that thymol attached membrane proteins in a hydrophilic way and changed permeability of the membrane of the microorganism $(2,12)$.

Most commonly studied phenyl propens include eugenol, isoeugenol, vanillin, safrole and cinnamaldehyde. Antibacterial activity of eugenol against 25 lineages of bacteria was studied showing no antimicrobial activity only against one lineage (13).

Isoeugenol and eugenol have considerable higher antimicrobial activity against Gram-negative bacteria, mold, and yeast than Gram-positive ones, while main elements of essences are naturally more active against Gram-positive bacteria $(14,15)$. Eugenol caused partial changes in characteristics of fatty acid in Pseudomonas fluorescens, Escherichia coli, Brochothrix thermosphacta, Salmonella enterica and Staphylococcus aureus and cellular damages in Escherichia coli and Brochotrix (16). Hydroxyl group of eugenol attached proteins and affected their characteristics.

Although high potential of essences and their compound have been confirmed in experimental studies, their application as food preservers faced some limitations in practice as high concentration of essences is needed to achieve adequate antimicrobial activity. Likewise, hydrophobic components of essences are deactivated with compounds in many food products such as fat, starch and proteins. In addition, antimicrobial potential of essence components depend on factors such as $\mathrm{pH}$, temperature and bacterial infection range (17). Therefore, using food models containing different quantities of fats, proteins or starch can be useful for designing experiments to identify certain essences in different products.

Food borne infections by sea foods are one of the most common reasons of gastrointestinal diseases (18). Vibrio bacteria are Gram-negative and anaerobic bacteria living in sea and fresh waters (19). Fojino introduced Vibrio parahaemolyticus (V. parahaemolyticus) for the first time in 1951 as the reason of stomach-intestinal inflammation resulted from consuming affected food. V. parahaemolyticus 
produces four types of hemolysins including thermostable direct hemolysin (TDH), TDH-related hemoly$\sin (\mathrm{TRH})$, thermolabile hemolysin (TLH) and $£-\mathrm{VPH}$ $(22.8 \mathrm{kDa})$. TDH is thermal resistance and sensitive to trypsin and its thermal stability is in a way that can remain in food after production and is tolerant to $100 \mathrm{oC}$ temperature in $\mathrm{pH}: 6$ and for $10 \mathrm{~min}(20,21)$. Fang et al. studied 777 sea foods and reported $54.7 \%$ V. parahaemolyticus contamination (22). Wong et al. investigated 686 sea foods and 315 samples of Vibrio parahaemolyticus (45.9\%) were isolated (23).

Regarding the presence of $V$. parahaemolyticus in sea food products and consequence health risks, this study tried to investigate the effect of lavender essence as a natural preserver on toxin formation and the growth of this pathogen.

\section{Material and Methods}

\section{Experimental Plan}

First the essence of lavender was prepared and the components were specified by GC MS instrument (Thermoquest Trace GC 2000 FINNIGAN, Eng.). Then, effect of lavender essence was studied on growth and toxin formation of Vibrio parahaemolyticus in concentrations of $0,0.005,0.015,0.03,0.045$ percent at $35 \mathrm{oC}$ in heart and brain broth over 24 hours.

\section{Preparing Lavender Essence}

The essence was prepared using hot vapor distillation using Clevenger instrument, Apparatus model Alright GMB / USA / United State.

\section{Identifying Essence Components}

Gas chromatograph instrument connected to mass spectrum (Thermoquest Trace GC 2000 FINNIGAN, Eng) was used to examine and analyze the components of essences. Thermo Quest Finnegan System with capillary column of $30 \mathrm{~m}$ long, internal diameter of $250 \mu \mathrm{m}$ and internal wall thickness of $0.25 \mu \mathrm{m}$ was used within thermal plan of $50 \mathrm{oC}$ to $26 \mathrm{oC}$ with gradual increase of $2.5 \mathrm{oC} / \mathrm{min}$ and maintaining the temperature of $265 \mathrm{oC}$ for 30 minutes. Injection module temperature was $250 \mathrm{oC}$ and helium was the carrier gas which passed through the pipe by $1.5 \mathrm{ml} / \mathrm{min}$.
Moreover, electrical capacity of the indicator was 70 $\mathrm{ev}$ and its ionization source temperature $205 \mathrm{oC}$.

\section{Studied Bacterium}

Studied bacterium was V. parahaemolyticus ATCC 43996. This bacterium was consecutively cultivated twice on heart and brain broth at $37 \mathrm{oC}$. Bacterium from the second culture was mixed with sterile glycerin with ratio of 1:5 and maintained in Eppendorf micro tubes of $500 \mu \mathrm{L}$ at $-20 \mathrm{oC}$.

\section{Preparing Bacterium Inoculation}

First the prepared bacterium at $-20 \mathrm{oC}$ was transferred to culture medium and maintained for 6 hours at 37 oC. Second, culture originated from the first broth and lasted for 6 hours at $37 \mathrm{oC}$. Then, different proportions of the second culture were transferred to Cuvette tubes containing $4 \mathrm{~mL}$ of heart and brain broth until light absorption of the Cuvette tube reached 0.1 at $600 \mathrm{~nm}$ using spectrophotometer instrument (Milton Ray Company, USA). Next, another culture was cultivated on heart and brain agar medium using $\mathrm{Cu}$ vette tubes so that bacterium quantity per millimeter of heart and brain broth was obtained according to correspondence Cuvette.

\section{Determining Minimum Inhibitory Concen- tration (MIC) Using Macro Dilution Method}

Consecutive concentrations of lavender essence ( 0 , $0.005,0.015,0.030$ and 0.045 percent) were prepared in two test tubes containing $2 \mathrm{~mL}$ of heart and brain broth medium with 5 percent DMSO (Dimethyl sulfoxide). Then, bacterium suspension was inoculated in tubes so that final bacterium concentration of $1 * 10^{5}$ $\mathrm{cfu} / \mathrm{mL}$ was reached. Next, tubes were incubated at $35 \mathrm{oC}$ for 24 hours and opacity in tubes was studied.

\section{Method of Determining Production and Tox- in Formation by Kit}

At first, $0.1 \mathrm{~mL}$ of tubes containing heart and brain broth was taken to determine the amount of toxin and the number of bacteria per $\mathrm{ml}$ of heart and brain broth was specified using dilution and cultivation method on BHI Agar medium. Then, Falcon tubes containing the remaining heart and brain broth were centri- 
fuged at $3000 \mathrm{rpm}$ for $20 \mathrm{~min}$. In microdilution technique, $25 \mu \mathrm{L}$ of dilutor was poured in two rows of microplate sinks (no dilutor was added to two first sinks of each row). Then, specified amount of upper liquid resulted from bacterium centrifuge was added to the two first sinks of each row and dilution was performed afterward. Next, $25 \mu \mathrm{L}$ of sensitize latex solution and $25 \mu \mathrm{L}$ of control latex added to sinks of the first and second rows, respectively. Afterward, 25 $\mu \mathrm{L}$ of pure toxin and $25 \mu \mathrm{L}$ of sensitize latex solution were poured in separate sinks as positive control; then microplate was kept in room temperature for 18 hours. Agglutination in each sink shows the presence of toxin and toxin dilution was calculated according to the location of the related sink and the protocol of kit Manufacturer (DENKA Seiken Japan).

\section{Determining Growth Chart}

At this stage, the effect of preventive concentrations of the lavender essence on the growth of $V$. parahaemolyticus was assessed over 24 hours. Therefore, 10 $\mathrm{mL}$ of prepared solutions containing different concentrations of the essence $(0,0.005$ and 0.015$)$ distributed in three tubes. Then, $100 \mu \mathrm{L}$ of bacterium suspension was added to each three tube (final bacterium concentration was $1 * 10^{5} \mathrm{cfu} / \mathrm{mL}$ ). Tubes were incubated at $35 \mathrm{oC}$ and related dilution was prepared from each 3 tubes at $0,1,2,3,4,6,8$ and 24 hours and cultivated on a plate containing $\mathrm{BHI}$ agar medium. Colony count was performed after 24-hour incubation at 35 $\mathrm{oC}$ and the number of bacteria was calculated at each considered hour.

\section{Statistical Analysis}

Data analysis was performed by SPSS v.22 (IBM company, USA SPSS Inc, Chicago,IL) using one-way analysis of variance (ANOVA) and Tukey Test.

\section{Results}

\section{Analyzing the Components of Lavender Essence}

Different components of lavender essence were analyzed by gas chromatograph connected to mass spectrometer. Accordingly, cineol with 49.16 percent had the highest concentration. After that borneol with 10.75 percent, camphor with 8.94 percent, linalool L with 3.95 percent and alpha-pinen with 3.2 had the highest amounts in the essence (Figure 1 and Table 1)

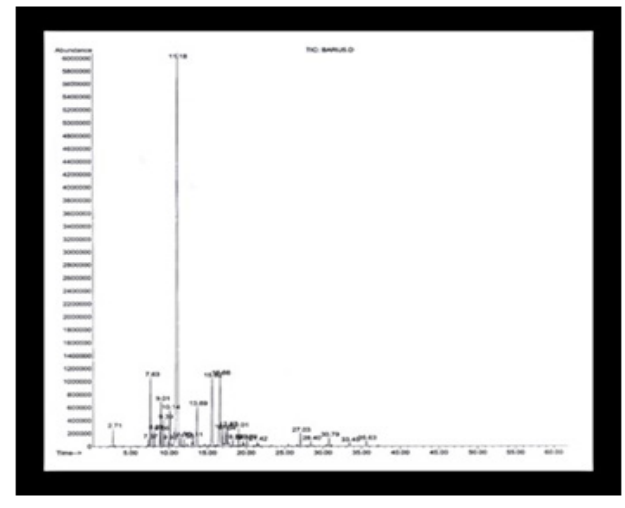

Figure 1. GC/MS Graph of Lavender Essence

Table 1. Chemical Compounds of Lavender Essence

\begin{tabular}{lcc}
\hline Chemical compound & Percent & Inetcepter index \\
\hline Alpha-thujene & 0.3 & 7.38 \\
\hline Alpha-pinen & 3.2 & 7.63 \\
\hline Camphene & 0.8 & 8.09 \\
\hline Sabinene & 0.9 & 8.85 \\
\hline Beta-pinen & 2.63 & 9.01 \\
\hline Beta-myrcene & 7.87 & 9.38 \\
\hline Alpha-phellandrene & 0.4 & 9.92 \\
\hline Delta-3-carene & 2.73 & 10.14 \\
\hline
\end{tabular}




\begin{tabular}{|lcc|}
\hline Chemical compound & Percent & Inetcepter index \\
\hline 1,8-cineole & 49.16 & 11.18 \\
\hline Ocimene $<$ (E)-B-> & 0.49 & 11.51 \\
\hline Alpha-terpinolene & 0.5 & 13.11 \\
\hline Linalool L & 3.95 & 13.69 \\
\hline Camphor & 8.94 & 15.63 \\
\hline Borneol & 10.75 & 16.66 \\
\hline Terpinen-4-ol & 1.04 & 16.97 \\
\hline Cryptone & 1.3 & 17.34 \\
\hline Alpha-terpineol & 1.16 & 17.56 \\
\hline Isophorone<4-methylene $>$ & 0.49 & 18.27 \\
\hline Unknown & 0.99 & 19.01 \\
\hline Cumin aldehyde & 0.38 & 19.56 \\
\hline Linalool acetate & 0.5 & 20.09 \\
\hline Thuganol acetate $<$ iso-3> & 0.23 & 21.42 \\
\hline Trans-caryophyllene & 0.93 & 27.03 \\
\hline Trans-beta-farnesene & 0.3 & 30.79 \\
\hline Gamma-cadinene & 0.58 & 35.45 \\
\hline Caryophyllene oxide & 0.33 & \\
\hline Cubenol<1,10-di-epi> & -53.7 \\
\hline Sum & & \\
\hline & & \\
\hline
\end{tabular}

\section{MIC Results of Lavender Essence on Growth and Toxin Formation of Vibrio Parahaemolyti-} cus

In this research, the effect of five different concentrations of lavender essence $(0,0.005,0.015,0.030$ and 0.045 percent) was assessed on growth and toxin formation of $V$. parahaemolyticus. Results showed that 0.03 percent and higher concentrations had the ability to prevent the growth of $V$. parahaemolyticus.

\section{The Effect of Lavender on TDH Titration}

Different concentrations of lavender essence had significant effect on the titration of produced toxin of $V$. parahaemolyticus, so that titration of produced toxin in concentrations of $0,0.005$ and 0.015 percent of lavender essence at $35 \mathrm{oC}$ were 1.256, 1.128 and 1.8 , respectively (Table 2 and Figure 2).

\section{V.parahaemolyticus Growth Chart Affected by Lavender Essence}

As shown in table 2, concentrations of 0.005 and 0.015 percent of lavender essence (under-interceptor concentrations) reduced bacterium growth significantly compared with the control group $(P<0.05)$, so that logarithm of bacterium number in these two concentrations at the fourth hour of incubation were 3.04 and 2.69, respectively; however, logarithm of bacterium growth in the mentioned hour for the control group was 7.74. Bacterium growth reduced from zero to sixth hour and increased from eighth hour. The difference of bacterium growth between the two concentrations of 0.005 and 0.015 percent of essence was not significant, but was significantly different between the two mentioned concentrations and the control group (Figure 3 and Table 3). 


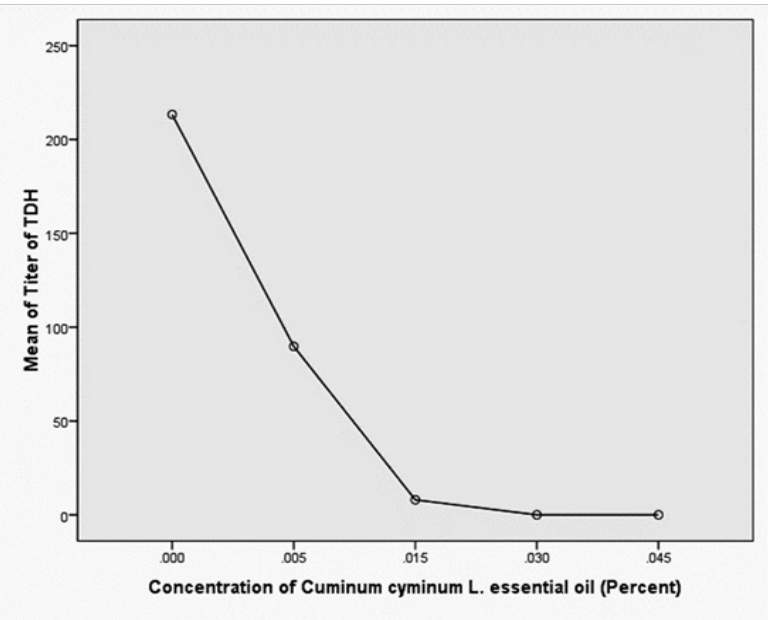

Figure 2. The Effect of Different Concentrations of Lavender Essence on TDH Titration

Table 2. TDH Titration Affected by Different Concentration of Lavender $(0,0.005,0.015,0.030$ and 0.045 percent) at $35 \mathrm{oC}$

\begin{tabular}{cccc}
\hline Bacterium per ml & OD & Titration of produced toxin & Lavender essence concentration \\
\hline $8.7 * 10^{8}$ & 0.86 & 1.256 & 0 \\
\hline $8.7 * 10^{8}$ & 0.86 & 1.128 & 0.005 \\
\hline $8.7 * 10^{8}$ & 0.86 & 1.8 & 0.015 \\
\hline- & - & No growth & 0.03 \\
\hline- & - & No growth & 0.045 \\
\hline
\end{tabular}

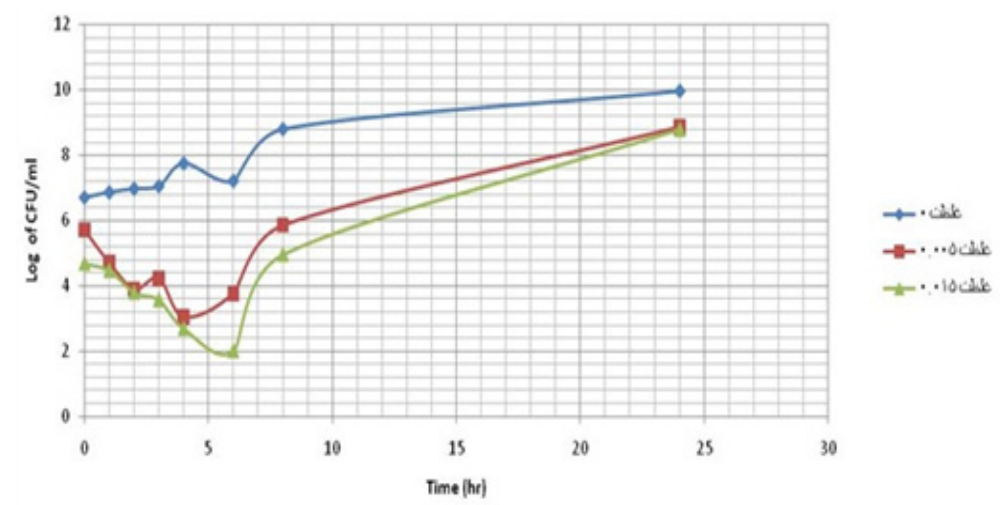

Figure 3. Vibrio Parahaemolyticus Growth Chart Affected by Different Concentrations of Lavender Essence (0, 0.005 and 0.015) During 24 Hours

Table 3. Vibrio Parahaemolyticus Growth Chart Affected by Different Concentrations of Lavender Essence $(0,0.005$ and 0.015) During 24 Hours

\begin{tabular}{ccccccccc}
\hline Concentration Time & Zero & $\mathbf{1}$ & $\mathbf{2}$ & $\mathbf{3}$ & $\mathbf{4}$ & $\mathbf{6}$ & $\mathbf{8}$ & $\mathbf{2 4}$ \\
\hline Zero & $4.9^{*} 10^{6}$ & $7.2^{*} 10^{6}$ & $9.2 * 10^{6}$ & $1.1 * 10^{7}$ & $5.5^{*} 10^{7}$ & $1.6^{*} 10^{7}$ & $6.2^{*} 10^{8}$ & $9.3^{*} 10^{9}$ \\
$\mathbf{0 . 0 0 5}$ & $5.2 * 10^{5}$ & $5.1 * 10^{3}$ & $8 * 10^{3}$ & $1.7 * 10^{3}$ & $1.1 * 10^{3}$ & $6 * 10^{3}$ & $7.3 * 10^{5}$ & $7.7^{*} 10^{8}$ \\
$\mathbf{0 . 0 1 5}$ & $4.8^{*} 10^{3}$ & $3 * 10^{3}$ & $6.3 * 10^{3}$ & $3.8^{*} 10^{3}$ & $5 * 10^{2}$ & $1 * 10^{2}$ & $9.3 * 10^{3}$ & \\
\hline
\end{tabular}




\section{Discussion}

One of the most important food borne pathogens is V. parahaemolyticus, which leads to food poisoning by consuming fish and its products and other sea foods infected by the bacterium. This bacterium leads to gastroenteritis. As some food products are consumed half-baked or even raw, there is always the risk of infection. There have been many reports of isolating this bacterium from sea foods around the world. In a study by American Food and Drug Association performed on 635 samples of sea foods, $86 \%$ contained $V$. parahaemolyticus (18). Increase of microbial growth in food harms people health and national economy, which necessitates maintaining the quality and surveillance strategies. In this study, the effect of different concentrations of lavender essence was assessed on the growth and toxin formation of $V$. parahaemolyticus with incubation of 105 in vitro. This study methodology is similar to Osawa et al. who used ELISA method, Kap-Rpla Kit (24).

In this study, titration of TDH (toxin formation) in concentrations of zero, 0.005 and 0.015 percent were $1: 8,1: 128$ and 1:256, respectively, but no toxin formation was observed in 0.030 and 0.045 percent. Bacterium growth diagram also showed considerable growth decrease in concentrations of 0.005 and 0.015 percent in comparison with control group during 24 hours, especially at sixth hour.

Many studies have been performed to investigate the effect of different compounds on the growth and toxin formation of $V$. parahaemolyticus (25).

Antibacterial effects against $V$. parahaemolyticus have been reported using different oily essences such as rosemary, oregano, clove, horse radish and Garlic (26).

Yutaka et al. studied antibacterial effects of 18 vegetative species on V. parahaemolyticus. Consequently, basil, clove, garlic, horse radish, marjoram, oregano, rosemary and thyme showed antibacterial effects at 30 oC. The lowest MIC was $0.125 \%$ related to clove and marjoram in an environment rich in nutrients. Decreasing maintenance temperature has little effect on minimum intercepter concentration except for tur- meric. Sensitivity to different essences was the same between different clinical serotypes (27).

Antimicrobial activity of fresh garlic and lemon extracts on lineage of $V$. parahaemolyticus pandemics was studied using disc diffusion technique indicating that the two extracts prevented growth of $V$. parahaemolyticus (28).

Al-Jedah et al. studied fish sauce inoculation $\left(1 * 10^{4}\right.$ cfu/mL) with E. coli, S. typhi form, Staphylococcus aureus and $V$. parahaemolyticus showing that spices and other compounds (wheat and lemon) had preventive effects on corresponding pathogens and only V. parahaemolyticus remained alive after 7 hours at $250 \mathrm{oC}$ and was identified after 21 days. However, all of these pathogens in the control group except Staphylococcus aureus remained alive until 28 days (29).

Antibacterial effects of combined extracts of cranberry and oregano on $V$. parahaemolyticus were studied showing that antibacterial activity of the combination of these two extracts was more than each one alone, also the efficiency of these two extracts with lactic acid was higher (30).

Rattanachaikunsopon et al. studied antimicrobial activity of an oily garlic essence against Vibrio cholerae in vitro and in food model. Fatal effect on different lineages of $V$. cholerae was confirmed in vitro with MIC of 3.13 to $25 \mu \mathrm{g} / \mathrm{mL}$, also the essence reduced the number of bacteria in food model (31).

According to Badiee, cumin essence in concentrations of 0.005 and 0.015 percent reduced toxin formation of $V$. parahaemolyticus at $37 \mathrm{oC}$ (32).

Effect of different concentrations of Shirazian thyme essence on $V$. parahaemolyticus growth was studied in BHI medium indicating that the essence could prevent bacterium growth (33).

Imelouane et al. studied antibacterial effect of lavender essence using propagation method in solid medium and it was found that the essence prevented bacterial growth of Listeria monocytogenes, Haemophilus influenza, Neisseria meningitidis and different species of Streptococcus (34).

In Rasooli and Rezaee investigation, antibacterial activity of lavender essence on the growth of $S$. au- 
reus and E. coli was studied using MIC and MBC methods; MIC was 0.030 (35).

According to the report of Food Health Codex Committee, even small amount of $V$. parahaemolyticus in raw sea food makes its unusable (30).

In a study by Dixon, infectious dosage of V. parahaemolyticus was reported as 107 to 105 in raw and cooked sea food (36).

Kaneko showed that ingestion of $2 * 10^{5}$ to $3 * 10^{7}$ number of positive $V$. parahaemolyticus Kanagawa bacteria led to quick symptoms of gastroenteritis, while volunteers eating $1.6^{*} 1010$ numbers of $V$. parahaemolyticus bacteria only showed diarrhea (37).

Most common method of extracting essences in industry is distillation. In the present study, components of lavender essence were identified using GC mass instrument and the resulted decomposed composition included 49.16\% 1,8-cineol, 10.75\% borneol, 8.94\% camphor, $9.53 \%$ linalool $\mathrm{L}$ and $3.2 \%$ alpha-pinen. Lavender essence resulted from distillation was a yellow or greenish yellow liquid.

Gorena et al. analyzed components of lavender using gas mass spectroscopy and most common parts were menthol, beta-pinon and menthon (38).

Imelouane et al. identified 29 constituents in lavender oily essence in which gama-cineol with $41.28 \%$ had the highest amount and p-chlorophenyl was the least one (34).

In conclusion we found that lavender essence was able to prevent the growth and toxin formation of Vibrio parahaemolyticus in vitro. This finding encourages us to evaluate inhibitory effects of such natural substances on this organism in vivo.

Other pathogenic species of Vibrio including V. cholerae are among most common food and water borne bacterial pathogens in our country (39-43). Similar studies are suggested to determine antibacterial effects of lavender essence on endemic pathogenic $V$. cholera in the future.

\section{Conflict of interest}

the authors declare that there is no conflict of interests.

\section{References}

1. Kalemba D, Kunicka A. Antibacterial and antifungal properties of essential oils. Curr Med Chem. 2003;10(10):813-29. https://doi. org/10.2174/0929867033457719 PMid:12678685

2. Oussalah M, Caillet S, Saucier L, Lacroix M. Inhibitory effects of selected plant essential oils on the growth of four pathogenic bacteria: E. coli O157: H7, Salmonella typhimurium, Staphylococcus aureus and Listeria monocytogenes. Food Control. 2007;18(5):414-20. https:// doi.org/10.1016/j.foodcont.2005.11.009

3. Burt S. Essential oils: their antibacterial properties and potential applications in foods - a review. Int J Food Microbiol. 2004;94(3):223-53. https://doi.org/10.1016/j.ijfoodmicro.2004.03.022 PMID:15246235

4. Donsì $\mathrm{F}$, Annunziata $\mathrm{M}$, Sessa M, Ferrari G. Nanoencapsulation of essential oils to enhance their antimicrobial activity in foods. LWT-Food Science and Technology. 2011;44(9):1908-14. https://doi.org/10.1016/j.lwt.2011.03.003

5. Tajkarimi MM, Ibrahim SA, Cliver DO. Antimicrobial herb and spice compounds in food. Food control. 2010;21(9):1199-218. https://doi. org/10.1016/j.foodcont.2010.02.003

6. Hyldgaard M, Mygind T, Meyer RL. Essential oils in food preservation: mode of action, synergies, and interactions with food matrix components. Front Microbiol. 2012;3:12. https://doi. org/10.3389/fmicb.2012.00012 PMID:22291693 PMCID:PMC3265747

7. Khan Z, Saeed MA. Antibacterial potentials of some constitutents of Lavandula stoechas L. Pakistan Journal of Botany (Pakistan). 2002;34(4):359-66.

8. Cristani M, D'Arrigo M, Mandalari G, Castelli F, Sarpietro MG, Micieli D, Venuti V, Bisignano G, Saija A, Trombetta D. Interaction of four monoterpenes contained in essential oils with model membranes: implications for their antibacterial activity. J Agric Food Chem. 2007;55(15):6300-8. https://doi.org/10.1021/ jf070094x PMID:17602646

9. Burt SA, van der Zee R, Koets AP, de Graaff AM, van Knapen F, Gaastra W, Haagsman HP, 
Veldhuizen EJ. Carvacrol induces heat shock protein 60 and inhibits synthesis of flagellin in Escherichia coli O157: H7. Appl Environ Microbiol. 2007;73(14):4484-90. https://doi. org/10.1128/AEM.00340-07 PMID:17526792 PMCID:PMC 1932834

10. Mourey A, Canillac N. Anti-Listeria monocytogenes activity of essential oils components of conifers. Food Control. 2002;13(4-5):289-92. https://doi.org/10.1016/S0956-7135(02)00026-9

11. Ben Arfa A, Combes S, Preziosi-Belloy L, Gontard N, Chalier P. Antimicrobial activity of carvacrol related to its chemical structure. Lett Appl Microbiol. 2006;43(2):149-54. https://doi.org/10.1111/j.1472-765X.2006.01938.x PMID: 16869897

12. Ooi LS, Li Y, Kam SL, Wang H, Wong EY, Ooi VE. Antimicrobial activities of cinnamon oil and cinnamaldehyde from the Chinese medicinal herb Cinnamomum cassia Blume. Am J Chin Med. 2006;34(03):511-22. https://doi.org/10.1142/S0192415X06004041 PMID: 16710900

13. Laekeman GM, Van Hoof L, Haemers A, Berghe DV, Herman AG, Vlietinck AJ. Eugenol a valuable compound for in vitro experimental research and worthwhile for further in vivo investigation. Phytother Res. 1990;4(3):90-6. https://doi.org/10.1002/ptr.2650040304

14. Walsh SE, Maillard JY, Russell AD, Catrenich CE, Charbonneau DL, Bartolo RG. Activity and mechanisms of action of selected biocidal agents on Gram-positive and-negative bacteria. J Appl Microbiol. 2003;94(2):240-7. https://doi.org/10.1046/j.1365-2672.2003.01825.x PMID: 12534815

15. Fitzgerald DJ, Stratford M, Gasson MJ, Ueckert J, Bos A, Narbad A. Mode of antimicrobial action of vanillin against Escherichia coli, Lactobacillus plantarum and Listeria innocua. J Appl Microbiol. 2004;97(1):104-13. https://doi.org/10.1111/j.1365-2672.2004.02275.x PMID: 15186447

16. Di Pasqua R, Betts G, Hoskins N, Edwards M, Ercolini D, Mauriello G. Membrane toxicity of antimicrobial compounds from essential oils. J Agric Food Chem. 2007;55(12):4863-70. https://doi.org/10.1021/jf0636465 PMID: 17497876

17. Eisenhut M. The toxicity of essential oils. Int J Infect Dis. 2007;11(4):365. https://doi. org/10.1016/j.ijid.2006.07.004 PMID:17321181

18. Scallan E, Hoekstra RM, Angulo FJ, Tauxe RV, Widdowson MA, Roy SL, Jones JL, Griffin PM. Foodborne illness acquired in the United States-major pathogens. Emerg Infect Dis. 2011;17(1):7. https://doi. org/10.3201/eid1701.P11101 PMID:21192848 PMCID:PMC3375761

19. Yeung M, Boor KJ, Faruque SM. Epidemiology, molecular biology and detection of foodborne Vibrio parahaemolyticus infections. Foodborne and Waterborne Bacterial Pathogens: Epidemiology, Evolution and Molecular Biology. 2012:153-84.

20. Broberg CA, Calder TJ, Orth K. Vibrio parahaemolyticus cell biology and pathogenicity determinants. Microbes Infect. 2011;13(12-13):9921001. https://doi.org/10.1016/j.micinf.2011.06.013 PMID:21782964 PMCID:PMC3384537

21. Zhang L, Orth K. Virulence determinants for Vibrio parahaemolyticus infection. Curr Opin Microbiol. 2013;16(1):70-7. https://doi. org/10.1016/j.mib.2013.02.002 PMID:23433802

22. Fang SW, Huang WW, Chen LH. Contamination of seafood by Vibrio parahaemolyticus in Taiwan. Zhonghua Min Guo Wei Sheng Wu Ji Mian Yi Xue Za Zhi. 1987;20(2):140-7. PMID: $\underline{3652783}$

23. Wong HC, Liu SH, Ku LW, Lee IY, Wang TK, Lee YS, Lee CL, Kuo LP, Shih DY. Characterization of Vibrio parahaemolyticus isolates obtained from foodborne illness outbreaks during 1992 through 1995 in Taiwan. J Food Prot. 2000;63(7):900-6. https://doi.org/10.4315/0362028X-63.7.900 PMID: $\underline{10914657}$

24. Osawa R, Okitsu T, Morozumi H, Yamai S. Occurrence of urease-positive Vibrio parahaemolyticus in Kanagawa, Japan, with specific reference to presence of thermostable direct hemolysin (TDH) and the TDH-related-hemolysin genes. Appl Environ Microbiol. 1996;62(2):7257. PMID: $\underline{593076}$ PMCID:PMC167841

25. Vyas P. Essential oils from plants: A Review. In- 
ternational Journal of Chemtech Applications. 2013;2(1).

Yano Y, Satomi M, Oikawa H. Antimicrobial effect of spices and herbs on Vibrio parahaemolyticus. Int J Food Microbiol. 2006;111(1):6-11. https://doi.org/10.1016/j.ijfoodmicro.2006.04.031 PMID: 16797760

27. Bagamboula CF, Uyttendaele M, Debevere J. Antimicrobial effect of spices and herbs on Shigella sonnei and Shigella flexneri. J Food Prot. 2003;66(4):668-73. PMID:12696694

28. Vuddhakul V, Bhoopong P, Hayeebilan F, Subhadhirasakul S. Inhibitory activity of Thai condiments on pandemic strain of Vibrio parahaemolyticus. Food Microbiol. 2007;24(4):413-8. https://doi.org/10.1016/j.fm.2006.04.010

Al-Jedah JH, Ali MZ, Robinson RK. The inhibitory action of spices against pathogens that might be capable of growth in a fish sauce (mehiawah) from the Middle East. Int J Food Microbiol. 2000;57(1-2):129-33. https://doi. org/10.1016/S0168-1605(00)00231-2

Lean JM, Jagger CJ, Kirstein B, Fuller K, Chambers TJ. Hydrogen peroxide is essential for estrogen-deficiency bone loss and osteoclast formation. Endocrinology. 2005;146(2):72835. https://doi.org/10.1210/en.2004-1021 PMID: 15528306

31. Rattanachaikunsopon P, Phumkhachorn P. Antimicrobial activity of elephant garlic oil against Vibrio cholerae in vitro and in a food model. Biosci Biotechnol Biochem. 2009;73(7):1623-7. https://doi.org/10.1271/ bbb.90128_PMID: $\underline{19584531}$

32. Badiei B. The effect of different concentrations of Cumin and Nisin on the toxigenesis of Vibrio parahaemolyticus in BHI. PhD thesis, 2012

33. Khanjari A, Akhundzadeh A. Effect of zataria multiflora Boiss. essential oil on $\log \mathrm{p} \%$ of Vibrio parahaemolyticus in BHI broth. Iran J Nutr Sci Food Technol. 2011;8(28):37-45. http:// fsct.modares.ac.ir/article-7-436-en.pdf

34. Imelouane B, Elbachiri A, Ankit M, Benzeid H, Khedid K. Physico-chemical compositions and antimicrobial activity of essential oil of eastern Moroccan Lavandula dentata. Inter- national Journal of Agriculture and Biology. 2009;11(2):113-8.

35. Rasooli I, Rezaei MB, Allameh A. Ultrastructural studies on antimicrobial efficacy of thyme essential oils on Listeria monocytogenes. Int J Infect Dis. 2006;10(3):236-41. https://doi. org/10.1016/j.ijid.2005.05.006 PMID: 16412677

36. Dixon LL. Microbiological Quality of Toroi: A Maori food delicacy [dissertation]. Hamilton New Zealand: The university ofwaikato; 2007.

37. Kaneko T, Colwell RR. The annual cycle ofVibrio parahaemolyticus in Chesapeake Bay. Microb Ecol. 1977;4(2):135-55. https://doi. org/10.1007/BF02014284 PMID:24231972

38. Gören AC, Topçu G, Bilsel G, Bilsel M, Aydoğmusç Z, Pezzuto JM. The chemical constituents and biological activity of essential oil of Lavandula stoechas ssp. stoechas. Z Naturforsch C. 2002;57(9-10):797-800. https://doi. org/10.1515/znc-2002-9-1007 PMID:12440714

39. Ranjbar R, Rahbar M, Naghoni A, Farshad S, Davari A, Shahcheraghi F. A cholera outbreak associated with drinking contaminated well water. Arch Iran Med. 2011;14(5):339-40. PMID:21888459

40. Pourshafie MR, Bakhshi B, Ranjbar R, Sedaghat M, Sadeghifard N, Yazdi JZ, Parzadeh M, Raesi J. Dissemination of a single Vibrio cholerae clone in cholera outbreaks during 2005 in Iran. J Med Microbiol. 2007;56(12):1615-9. https://doi. org/10.1099/jmm.0.47218-0 PMID: 18033829

41. Ranjbar RE, Pourshafie MR, Sadeghifard N, Karami A, Hamidian M, Izadi M, Parzadeh M, Jonaidi N. Molecular characterization of epidemic isolates of Vibrio cholerae $\mathrm{O} 1$ by arbitrarily primed PCR (AP-PCR). Iran J Public Health. 2008;37(2):83-7.

42. Ranjbar R, Naghoni A, Afshar D, Nikkhahi F, Mohammadi M. Rapid Molecular Approach for Simultaneous Detection of Salmonella spp., Shigella spp., and Vibrio cholera. Osong Public Health Res Perspect. 2016;7(6):373-

7. https://doi.org/10.1016/j.phrp.2016.10.002 PMID:28053842 PMCID:PMC5194224

43. Ranjbar R, Sadeghy J, Moghadam MS, Bakhshi B. Multi-locus variable number tandem repeat 
255. The Effect of Lavandula ...

analysis of Vibrio cholerae isolates from 2012

to 2013 cholera outbreaks in Iran. Microb Pat- hog. 2016;97:84-8. https://doi.org/10.1016/j.micpath.2016.05.023 PMID:27247094

\section{How to Cite This Article}

Maghsoudi O, Zeraatkar M, Dolatabadi M, Johari A, Barati Karizno M, Ranjbar R. The Effect of Lavandula Stoechas on Toxigenesis and the Growth of Vibrio Parahaemolyticus. Iranian Journal of Pathology, 2018; 13(2): 245-255. 